\title{
Record Keeping To Book Keeping To E-Records: What Next?
}

\author{
Oladele, Femi \\ Department of Accounting, Faculty of Social and Management Sciences, Bowen University, Iwo, Osun State
}

\begin{abstract}
Trends is a necessary for understanding a phenomenon as it traces the history, status quo and can fairly project into the future thereby giving basic understanding necessary for innovations. Record-keeping in accounting is a basic financial reporting function which this study strives to understand especially from the historical perspective to present practice and hopes to be able to project into the future.

This work is a theoretical review of the book-keeping function in financial reporting, and the study found that record keeping which was the basic means has advanced to the use of online real-time records of transactions and events. Concerning future projection, the study assumes a more sophisticated approach. There is a tendency to undermine the role-relevance of book-keepers by modern technological applications in business, which is a wonderful innovation, it should not erode the underlying essence and principles on which book-keeping and the accounting profession is built.
\end{abstract}

Keywords: book-keeping, e-records, record-keeping, trends, underlying essence and principles.

\section{Introduction}

Book-keeping is a part of the accounting function, which is usually the most basic and rudimentary and is carried on by an account clerk, data entry clerk or a book-keeper, but has an overarching impact on the financial reporting of an entity. It is the recording of business's activities and operations with respect to financials, that is, transactions and events. As an integral part of the accounting cycle (which is depicted in Fig 1) it provides data on which the Accountant works on for analysis and interpretation (Wood, 1972).

Data collection, processing, dissemination and use in today's business world are at an advanced level. However, we didn't get here overnight, there has been a "steady" transition from mere rudimentary record keeping to a level of book-keeping and now electronic records. The importance of technological advancement cannot be overemphasized in the emerging business environment which requires access to relevant, reliable, adequate, accurate, timely and sufficient information for management to aid the decision-making process.

It is imperative however to look back from where it all started. The place of history cannot be overemphasized as it keeps reminding us of where we began and the focal points of call which is the underlying essence and principles. Thoughts of the advancement in technology floods my mind, however, it is imperative to have an idea of how it all evolved. Most students appreciate the use of information systems (IS) and information technology (IT) in business however they live in oblivion of the history of information systems, which could be attributed to abundance of applications (software) as business solutions. The application of information systems in business is not novel, it has been in existence, as Wood (1972) made reference in his book to the use of electronic computers for book-keeping and accounting functions, but in order not to lose the basic relevance and substance of book-keeping, it is important to take a proper back look.

Presently, business is suave with use of online real time identification and recording of transactions and events and one tends to wonder if there will be anything more excellent than this in the nearest future and that's why this review tries to ascertain if those business managers in the past using all those manual systems and punched cards felt professional then than now. As an Accountant now, the feel is to consider those processes time consuming and awkward, but they felt cool about it, how relevant then are those systems of information procession now than they were then?

\section{Statement Of The Problem}

There is a tendency among young generation of Accountants to lose touch with the real essence of book-keeping, because of obsession with advanced technological application as we might become too engrossed in the euphoria of modern technology application as business solutions, thereby neglecting the core principles of book-keeping. The above submission is in tandem with the expression by Wood (1972).

There is also the tendency to undermine the Book-keeper/Accountant, since most of their functions can be and have been automated. This fear, which might come true, as evident in some entities having staff who do not have educational/academic background in accounting as accounting staff, which if not checked could result to the relegation of the professional status enjoyed by Accountants. It is relevant to assert here that there are 
many applications (software) that have been developed to carry on the functions of book-keeping, which is a welcome development but poses a threat to the relevance of Accounts clerks.

Finally and most importantly, to this research is the tendency that geeks who develop software to carryon book-keeping functions in the pursuit of more sophisticated advanced book-keeping functionality and interface may find it necessary to emasculate the underlying essence and principles (UEP), just as Claver, Llopis \& González (n. d.) posited that "unfortunately, in many cases IS is implemented following technicians' analyses and considerations, with little if any regard for end users". It is imperative to state clearly that the consequence is grossly grave.

\section{Scope}

One basic question this review considers is "if information systems in the past was relevant in decision making now than it was in the past". The method of record keeping in the past provided information for decision making to managers on a manual base, how relevant is that now and does it have a greater relevance today than before?

This review will also consider the relevance of underlying essence and principles of book-keeping to today's approaches and applications.

Scope will include reviewing the history of business and the information processing system in use in the past. However, "past" is a relative term hence this review will consider businesses from the $18^{\text {th }}$ Century to $21^{\text {st }}$ Century. It will effectively reason out the methods in use then and now following the trend from record keeping to book-keeping and then to e-records.

\section{Objectives Of The Study}

On the whole the objective of this study is to review the information system in business in use before the advent of computers and evaluate the trend till date, projecting into the future.

Specifically this study will:

1. Emphasize the relevance of underlying essence and principles (UEP) of book-keeping;

2. Highlight the importance of information processing as a veritable tool for business solutions;

3. Highlight the media for provision of information for businesses; and

4. Review the history of information processing, and focus on breaking new grounds in information systems for business.

\section{Accounting: involving book-keeping}

\section{Theoretical Review}

Though this study strives to emphasize the book-keeping function; since it is a part of the accounting function, its relevance here as a subject matter is justified. It is also necessary to lay a basic foundation of expressing the whole picture of the cycle so as to make explicit the impression the book-keeping function has on the final outcome of a financial reporting endeavor.

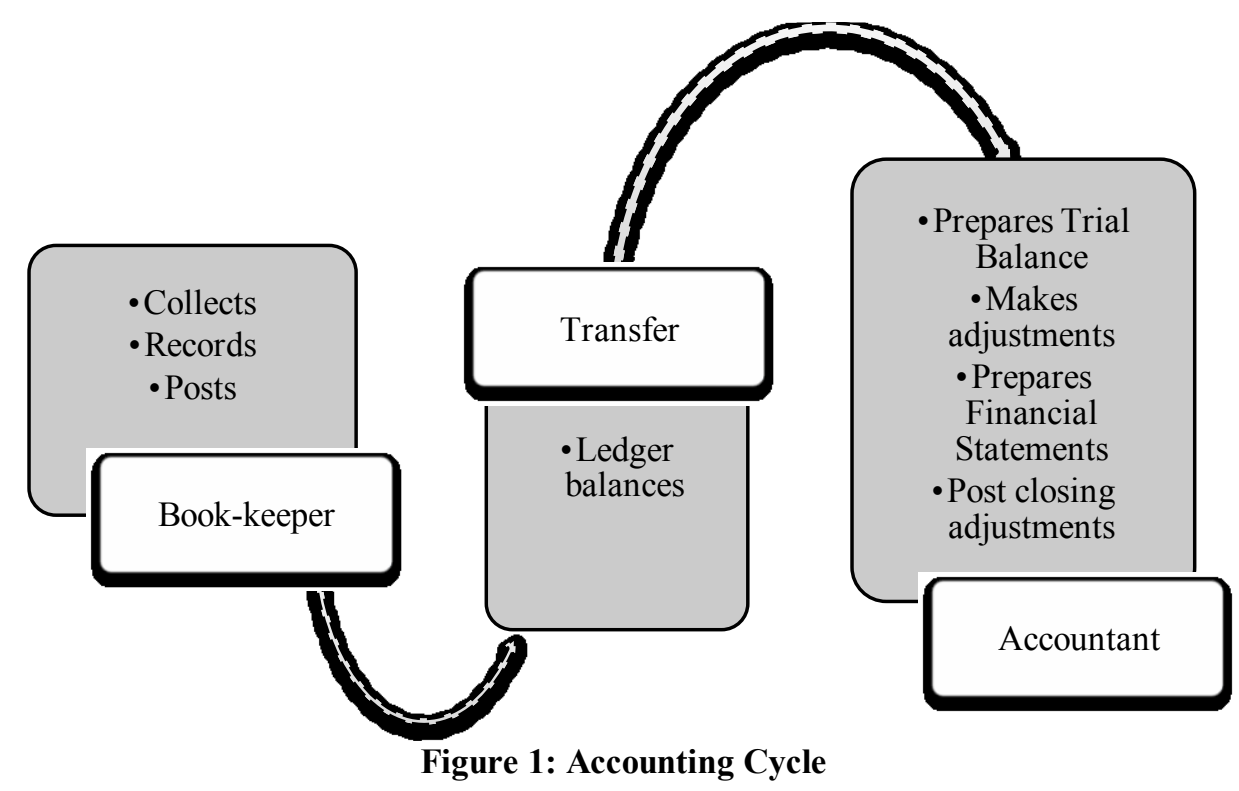


Having an overarching impression on the final outcome of the financial reporting process, operations and activities gives credence to understudy this great phenomenon as it were. Imagine an instance, when the Book-keeper commits errors, then the Accountant will also present incorrect/incomplete report to management, owners and other stakeholders. Though it is basic in nature, it has a principal role in determining the reliable outcome.

In collecting, recording and posting transaction and event records of an entity, the Book-keeper should never forget the underlying essence and principles.

\title{
Record keeping
}

Here, it simply implies the elementary keeping of transactions and events, which is most times on a single entry basis or an incomplete basis. According to Wood (1972), keeping records of transactions and events on such basis "can hardly be graced with the word system."

\author{
Book-keeping \\ keeping" \\ Wood (1972) submitted that "the actual record making phase of accounting is usually called book-
}

\section{E-records} article.

Automation of book-keeping activities and operations in an entity is regarded as e-records in this

There might not be literature on e-records in itself but the implication is the use of computer-based information systems for events recognition and transactions recording. It is the application of information technology for business processes. A definition of Information Systems (IS) might be very appropriate for erecords since e-records simply refer to electronic records, which is synonymous to the applications of information technology.

\section{Regulatory and Statutory frameworks for financial reporting}

There are several frameworks ranging from institutional to statutory, concerning financial reporting. However, changing business requirements drive the adoption of e-records rather than statutes. Businesses can still be complacent with traditional manual systems of book-keeping which is still evident in some institutions especially in the public sector in Nigeria, as most have only implemented partial automation, but changing information requirements and needs, modern advancements and other socio-cultural factors drive adoption and implementation of IT. It might be parochial for a Government to insist on e-records as most organizations are coming to the realization of its contributions to businesses, the following works have critically highlighted various contributions of IT/IS to business development (Kundishora, n. d.; Melville, Kraemer \& Gurbaxani, 2004; Ghanim, 2009; Claver, Llopis \& González, n. d. )

However, in Nigeria, after the adoption and part implementation of the drive for cashless economy policy, DMBs and other entities have been moving to comply with the use of Point of Sale (PoS) terminals, Automated Teller Machine (ATM), use of cards through mobile and online transactions and other electronic means of fund transfer. This could be said to be statutory since the Central Bank of Nigeria (CBN) who initiated the policy is a statutory institutional entity that have powers to regulate some sectors of the economy.

Also, with the adoption and implementation of the International Financial Reporting Standards (IFRSs), it will be quite inconvenient to stick to the traditional manual system of book-keeping and still meet information needs deadline.

\section{Underlying essence and principles (UEP) of book-keeping}

In order not to be caught in the web of arbitrary development of record keeping systems that is technologically driven, and losing the core, the author suggests the reference to the basic substance of bookkeeping as underlying essence and principles. This is to allay the fear that most applications (software) that are developed to perform book-keeping function do not undermine these.

Wood (1972) referred to this concept as the "main ends" and said that "what is important is that the main ends which the financial book-keeping records purport to serve remain the same" and concluded that "it is the means by which the actual records are effected that can be altered" thereby supporting the author's submission that Accountants must ensure that these UEP must not be undermined in the development of record keeping applications (software).

International Accounting Standards Board (2011) posited that the "the objective of general purpose financial reporting is to provide financial information about the reporting entity that is useful to existing and potential investors, lenders and other creditors in making decisions about providing resources to the entity." This is the driving force of every book-keeping endeavor. The end is to be able to provide information that is 
required. The underlying essence and principles find themselves in between what is generally referred to as accounting concepts, conventions, basis and principles, with standards making an all encompassing banner over them.

It is necessary to stress these, because we must not lose the foundation on which the profession is built on the basis of looking for more sophisticated approaches. In essence, if an accounting or book-keeping application is tilting towards ignoring or undermining the UEP, then it should be totally rejected.

It is however not part of the objectives of this study to explain the UEP, but to emphasize its relevance in book-keeping.

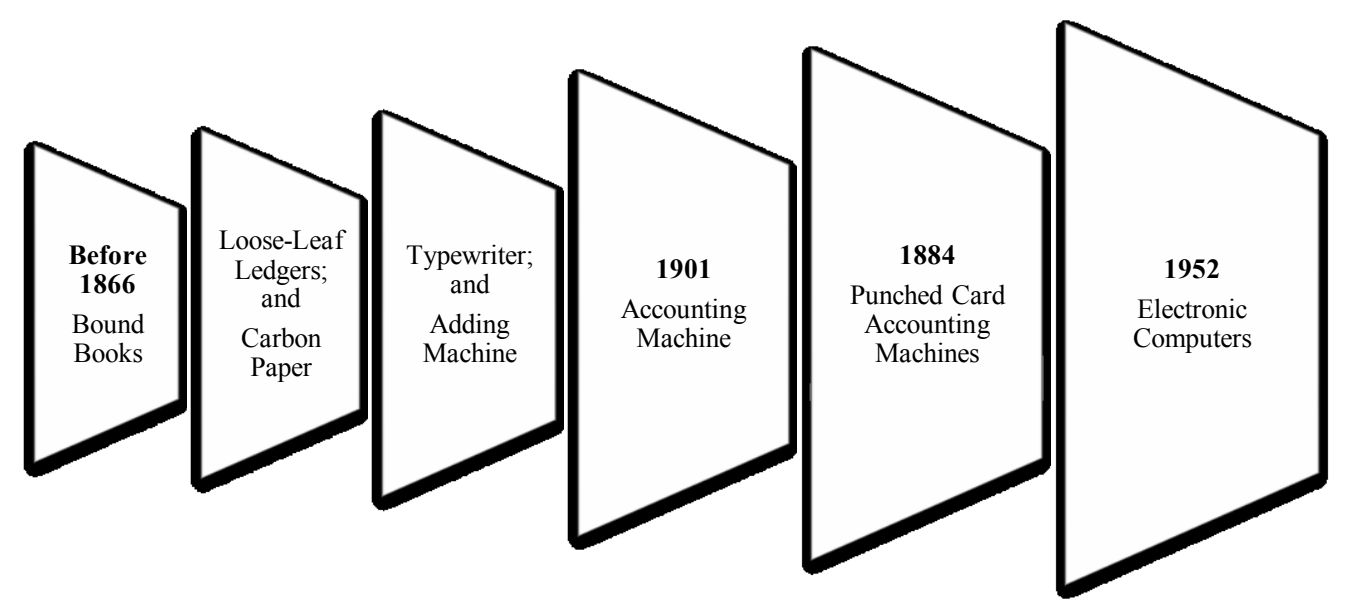

Source: Adapted from Wood (1972

Figure 2: Media Trends of Book-keeping

\section{Trends of Book-keeping}

Fig 2 above shows the trend of book-keeping approaches and media through the years. Through those years, the UEP was emphasized and should still be emphasized now. Due to changing developmental variables, information needs change and dynamics are required, but the stress here is that no matter the medium, UEP should be upheld. Also, it is apparent that information processing has become more robust with time.

\section{Empirical Review}

An empirical evidence of this kind is scarce as at the time of writing this, however, the contributions of Information Systems and Information Technology cannot be undermined as the current trend in business.

Developments have occurred in the applications of IT/IS to business operations and activities as Wood (1972) averred that "more modern methods have developed from the conventional system"

Melville et al (2004) in their study identified that a "principal finding is that IT is valuable" showing that IT and IS has gained prominence in the business world; it is now something that businesses strive for even Governments (Ghanim, 2009). It is necessary to state here that business were at some points complacent with manual systems as cybercrime became too prominent and scared them away, but with recent development, advancements and breakthroughs, those fears have been allayed and many businesses are now embracing erecords.

This wave is not only prominent for blue chip companies; even small businesses are joining in the action as according to Broida \& Stockstill (1994) that "the emergence of powerful personal computers is changing the way small businesses do accounting"

\section{Accounting record practices in Nigeria}

Most Deposit Money Banks (DMBs) in Nigeria, if not all, have adopted and implemented online real time basis of recording transactions and events, as well as most established entities, while high cost of equipment acquisition and cost of technical personnel servicing have been the bane to many small and medium sized entities.

The advantage is not farfetched. Considering a scenario when a bank customer goes to several branches of a bank to withdraw same amount of cash with an intent to defraud the bank; this can be curtailed if an immediate real time online reconciliation of the account is carried out. So when the customer makes a 
withdrawal, the account is immediately debited. This is however, one of many advantages of IT/IS implementation in business.

\section{Conclusions and Recommendations}

The place of information technology in business has brought about peculiar changes to the accounting professional skills and technical requirements especially with respect to auditing. Now prospective and prospecting Chartered Accountants especially in Nigeria are required to obtain a certification from a Computer Institute before they become bona fide members.

The author agrees that there might be a more sophisticated platform for accounting records as there is improvement by the day, however, existing Accountants can remain relevant by approaching the profession as they ought. The perception of the fact that Accountants are just mere counters of figures (number punchers) must be replaced with a strategic relevance to the benefits to societal cognizance. Also, in our struggle to attain global status, an Accountant must ensure that UEP are not ignored or undermined on the altar of technological advancement.

Technological advancements for business record keeping solutions are wonderful, but we must not allow this craze to undermine the underlying essence and principles of book-keeping. Also professional accounting bodies should strive to actualize the regulation of book-keeping software so as not to undermine the role of Accountants in society and deprive them of the status they enjoy as professionals.

\section{References}

[1]. Amongin, M. M. (2011). Computerised accounting and financial reporting, a case study of Stanbic Bank, Garden City branch, A research report submitted to Makerere University, in partial fulfillment of the requirements for the award of the degree of Bachelor of Commerce

[2]. Broida, M. S. \& Stockstill, L. E. (1994). Computerized Accounting Software in the 1990's: A Small Business Update

[3]. Claver, E., Llopis, J. \& González, M. R. (n. d.). The Performance of Information Systems through Organizational Culture

[4]. Ghanim, A. (2009). Impact of Information Technology on Corporate Performance: A Practical Study at Palestinian Firms, Impact of Information System, pp 1-52

[5]. International Accounting Standards Board (2011). The Conceptual Framework for Financial Reporting 2011, as issued at 1 January 2011 prepared by IFRS Foundation Staff (not yet approved by IASB)

[6]. Kundishora, S. M. (n. d.). The Role of Information and Communication Technology (ICT) in Enhancing Local Economic Development and Poverty Reduction, pp

[7]. Melville, N., Kraemer, K. L. \& Gurbaxani, V. (2004). Information Technology and Prganizational Performance: An Integrative Model of IT Business Value, available $\quad$ www.crito.uci.edu (accessed 20 May 2014)

[8]. Wood, F. (1972). Business Accounting 1, (2 ${ }^{\text {nd }}$ ed.) Longman Group Ltd, London 